\title{
Modeling Study of Diurnally Varying Convective Boundary Layer and Dust Transport over Desert Regions
}

\author{
Tetsuya Takemi ${ }^{1}$, Motoaki Yasui ${ }^{2}$, Jixia Zhou ${ }^{3}$ and Lichao Liu $^{3}$ \\ ${ }^{1}$ Department of Environmental Science and Technology, \\ Tokyo Institute of Technology, Yokohama, Japan \\ ${ }^{2}$ National Institute of Information and Communications Technology, Koganei, Japan \\ ${ }^{3}$ Cold and Arid Regions Environmental and Engineering Research Institute, \\ Chinese Academy of Sciences, China
}

\begin{abstract}
High-resolution simulations on the vertical transport of dust in a fair-weather condition over desert regions are performed with a cloud-resolving modeling approach. Basic processes relevant to the dust transport are examined by focusing on the role of boundary-layer and cloud convection. Although the model settings are simplified, the simulation well reproduces the diurnal variability of fair-weather convective boundary layer and cloud development observed over a Chinese desert. Dry convective motion within the boundary layer and moist convection above the boundary layer play a significant role in regulating the vertical mixing and transport of dust in the atmosphere, and in enhancing the surface winds and thus the dust emission by the downward transport of high momentum in upper levels. The present modeling framework is useful in understanding the small-scale effects on the vertical dust transport associated with boundary-layer convection and cloud convection in a fair-weather environment.
\end{abstract}

\section{Introduction}

The transport of dust from the surface to the free troposphere has been widely investigated through insitu observations, remote-sensing analyses, and numerical simulations from a planetary-scale to a synopticscale, and further down to a mesoscale perspective. A recent study by Takemi (2005) has focused, by performing three-dimensional cloud-resolving simulations, on the convective-scale transport of dust during the development of a mesoscale convective system that has a feature similar to the one that caused a disastrous duststorm over the Gobi Desert on 5 May 1993 (Takemi 1999).

Although synoptic-scale and mesoscale disturbances seem to play a major role in controlling the total amount of dust concentration and transport in source regions of mid-latitude deserts (e.g., Takemi and Seino 2005), small-scale, boundary-layer mixing is also responsible for dust emission (Cakmur and Miller 2004). Diurnal variability of dust mobilization and concentration is responsible for $20-50 \%$ of the total temporal variability in East Asia (Luo et al. 2004). Yasui et al. (2005) clearly demonstrated the diurnal variability of dust concentration in the planetary boundary layer in fairweather conditions through the lidar observations conducted at a desert site of Shapotou (at $37.46^{\circ} \mathrm{N}$ and $104.95^{\circ} \mathrm{E}, 1250 \mathrm{~m}$ above the sea level) in the south of the Tenger Desert, and pointed out that boundary-layer thermal convection plays a role in determining the vertical distribution of dust in those conditions.

Corresponding author: Tetsuya Takemi, Department of Environmental Science and Technology, Tokyo Institute of Technology, 4259-G5-7, Nagatsuta, Yokohama 226-8502, Japan. E-mail: takemi@ depe.titech.ac.jp. @2005, the Meteorological Society of Japan.
Considering that the boundary-layer tops over Chinese deserts sometimes reach up to over the 4-km height above the ground (Takemi and Satomura 2000) and that dust is well-mixed in the deep boundary layer (Yasui et al. 2005), the characteristics and strength of boundary-layer dry convection will regulate the vertical mixing and transport of dust within the boundary layer and the further upward transport above the boundary layer. Therefore, not only the synoptic-scale processes but also the small-scale transport processes, because of their prevalence over the deserts in East Asia, should be taken into account for the better numerical prediction and evaluation of the long-range transport of dust in the global atmosphere (e.g., Iwasaka et al. 2003).

In the present study, we will investigate dynamical processes and roles of convective mixing and updrafts on the vertical transport of dust with a cloud-resolving modeling approach coupled with a standard emission scheme for surface dust. High-resolution simulations on dust emission and transport in a simplified setup are performed without the help of cumulus and/or boundary-layer mixing parameterizations.

\section{Model and simulation setup}

The cloud-resolving model used here is a nonhydrostatic cloud model, the Advanced Regional Prediction System (ARPS, Xue et al. 2000). In order to focus on the fundamental dynamics of convective dust transport the model is run in an idealized setup. The model domain is $80 \mathrm{~km}$ in the $x$ (east-west) direction, 20 $\mathrm{km}$ in $y$ (north-south), and $18.4 \mathrm{~km}$ in $z$ (vertical), with the periodic condition imposed at the lateral boundaries, the rigid lid at the top boundary, and a Rayleigh-type damping layer in the upper part.

Parameterized physical processes include cloudmicrophysics (water and ice), short- and long-wave radiation transfer (calculated every 300 s), subgridturbulence mixing, surface momentum and scalar fluxes, and land-surface energy balance. Details of these parameterizations are found in Xue et al. (2001). The same schemes with those in Takemi (2005), but with the addition of the effects of diurnal variability from radiative energy transfer and surface energy exchanges, are used here. We ignore the Coriolis effect for simplicity.

We use a dust emission and transport module implemented in ARPS (Takemi 2005). Dust content is represented as mixing ratio, and the dust particle radius is assumed to be $1.0 \mu \mathrm{m}$ in order to represent a small-size particle which would be ready for long-range transport. The vertical dust flux at the surface is computed by the equation presented in Liu and Westphal (2001), and the friction velocity threshold for dust emission is given as a constant: $u_{* t}=60 \mathrm{~cm} \mathrm{~s}^{-1}$, following Liu and Westphal. In this study all the surface is assumed to be desert and dust erodible. 

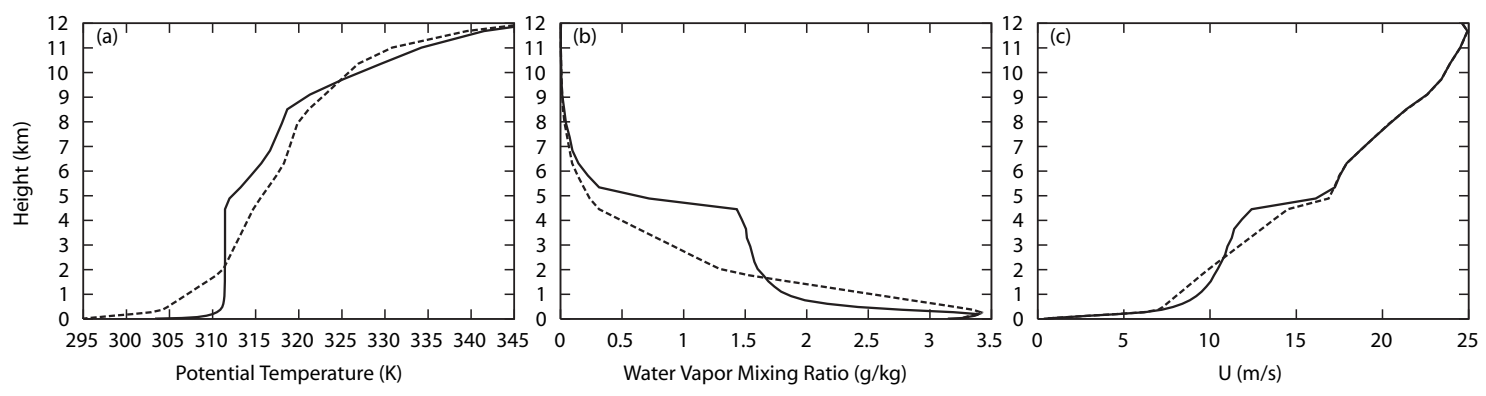

Fig. 1. Base-state vertical profiles of (a) potential temperature, (b) water vapor mixing ratio, and (c) east-west wind speed for the preliminary run (dashed, taken from the 00Z 13 April 2002 sounding) and the control run (solid).

The numerical schemes used here are the same with those in Takemi (2005), except for a flux-corrected positive definite scheme for advection terms of water variables, turbulent kinetic energy, and dust content. The horizontal grid size is $500 \mathrm{~m}$, which may be sufficient to resolve boundary-layer coherent convective motion, since Yasui et al. (2005) estimated its horizontal size as $4.3-7.3 \mathrm{~km}$. The vertical grid size is $20-810 \mathrm{~m}$ (stretched).

A horizontally homogeneous base state is defined with upper-air sounding data at the Yinchuan weather station near Shapotou. Following the analyses by Yasui et al. (2005), we use the sounding at 00Z 13 April 2002 to represent a deep mixed-layer structure in fine weather (Fig. 1). In order to maintain the initial conditions, the domain averaged profiles of horizontal velocity and water vapor mixing ratio are relaxed toward the initial profiles with time scales of 3 and 24 hours respectively for momentum and moisture, which can be regarded as a background large-scale forcing (Grabowski et al. 1996).

As a preliminary run, the model is run for 3 days without the dust calculation in order to obtain its equilibrium state, initialized by the Yinchuan sounding with random temperature perturbations added below $1 \mathrm{~km}$. The horizontal averages of the model after the preliminary 3-day integration are shown also in Fig. 1. With these profiles as the initial condition, the control simulation is performed for the next $24 \mathrm{~h}$ including the dust module. All the times here are referred to as a local time (LT=Beijing Time-1).

\section{Results}

At first the observations and the simulated results are compared in Figs. 2 and 3. Figure 2 shows the time series of temperature, wind speed, and relative humidity at the surface obtained both from the observation at Shapotou and the control simulation during 3 days and $24 \mathrm{~h}$, respectively. The period of 11-13 April 2002 is chosen for the observations, since fair-weather dry convection prevailed during these daytimes (Yasui et al. 2005); during this period the observational data clearly indicate a diurnal variability. The simulated results demonstrate that the model well captures this diurnal variability, despite the simplified model settings.

Figure 3 compares cloud amount derived from the lidar observation at Shapotou and the simulation. The cloud amount from the observation is determined by a percentage frequency of cloud detection among the total lidar observations in an hour, and that from the simulation determined by a percentage area of the cloud-water plus cloud-ice content greater than $0.01 \mathrm{~g}$ $\mathrm{kg}^{-1}$ at the $6-\mathrm{km}$ and $8-\mathrm{km}$ levels. The observed cloud amount was not available in the afternoon hours,
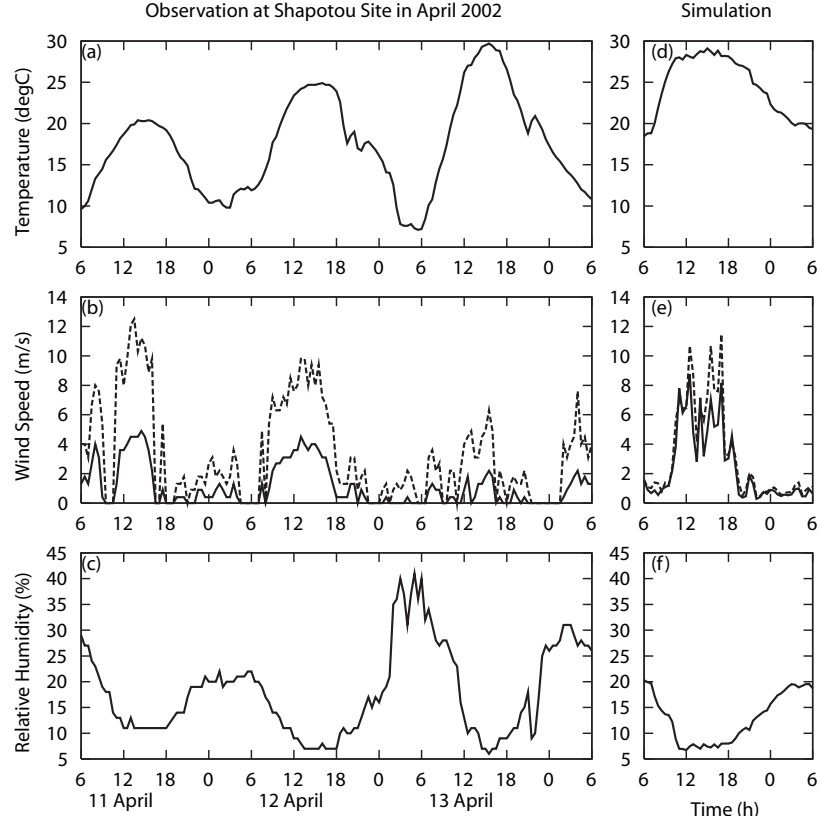

Fig. 2. Time series of the surface changes (temperature, wind speed, and relative humidity) at the Shapotou observation site (left column) and obtained at the domain center of the control simulation (right column). In (b) and (e) the maximum (dashed) and mean (solid) wind speeds for every 30 min are shown.

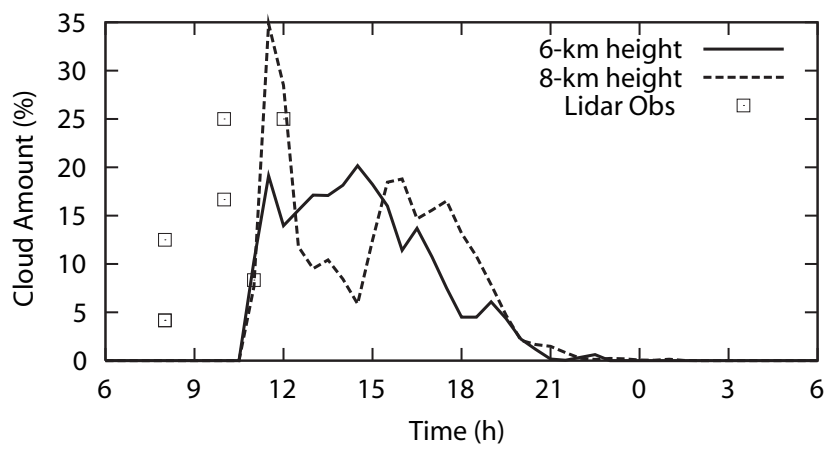

Fig. 3. Time series of cloud amount derived from the lidar observation during 11-13 April (squares) and the simulation (solid and dashed lines). Note that the lidar estimations were not available due to dust suspended in the air. 


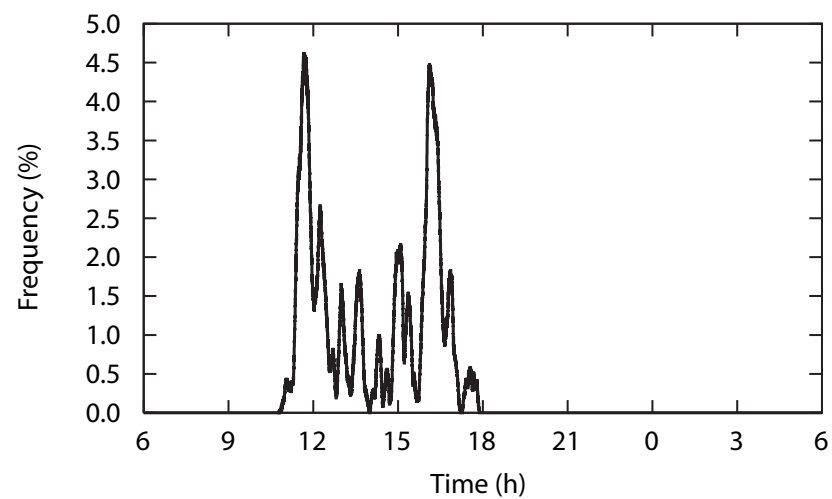

Fig. 4. Time series of the percentage frequency of friction velocity greater than $u_{*}$ in the model area.

because of dust floating in the boundary layer. This comparison also indicates that the model successfully simulates the basic features of the diurnal variability. Moreover, the simulated boundary-layer depth is comparable to the lidar observations (not shown). Thus, the simulation is useful in examining the dust transport processes relevant to boundary-layer convection. In the following the results of the control simulation are presented.

The amount of dust uplift from the surface critically depends on the strength of surface friction velocity. Figure 4 shows the diurnal variation of the frequency of the friction velocity greater than the threshold $u_{* t}$ in the model area. At about 10:50 LT there appear grid locations at which the friction velocity exceeds $u_{*}$, and thus surface dust flux occurs; at 11:40 the percentage frequency reaches the maximum of 4.63\%; in afternoon hours it significantly varies; and after about 17:50 friction velocity that exceeds the threshold diminishes. All in all, the percentage area for surface dust emission is as high as about $5 \%$ in the $80 \mathrm{~km}$ by $20 \mathrm{~km}$ area and strongly varies mostly between $0-2 \%$ during the afternoon periods.

The temporal evolution of cloud, dust concentration and upward dust flux is examined in Fig. 5: the areaaveraged values at each height are shown, and the cloud boundary is defined as the contour of the cloud-water and cloud-ice mixing ratio of $0.01 \mathrm{~g} \mathrm{~kg}^{-1}$. Dust, once emitted at the surface, is quickly raised and mixed up to the cloud-base level (about 5-km height) by active convective motion in the boundary layer. During 12-18 LT the dust concentration in the boundary-layer generally increases, and a large amount of dust flux is seen below the 4-km level. From the signs of cloud boundary and vertical dust flux, the dust transport above the cloud-base level seems to be regulated by the vertical extent of cloud upward motions in the afternoon: the gradual increase of dust concentration above the $5-\mathrm{km}$ level (i.e., the free troposphere) well corresponds to the upward dust flux and cloud development during 12-17 LT.

It is seen in Fig. 5 that the dust concentration after sunset (i.e., about $18 \mathrm{LT}$ ) shows a steady, stratified structure. Hence the dust budget can be estimated in one diurnal cycle. Figure 6 shows the temporal variation of the mean column burden of dust and the percentage ratio of the total dust content in the $0-2,2-4,4-6$, and 6-12 $\mathrm{km}$ layer to the accumulated surface dust emission. Each layer represents the lower and upper part of the boundary layer, the transition layer around cloud base, and the free troposphere. The mean dust burden steadily increases and reaches up to $0.92 \mathrm{~g} \mathrm{~m}^{-2}$ (Fig. 6a). During the first 2 hours after the outbreak of surface dust emission, more than $85 \%$ of the total

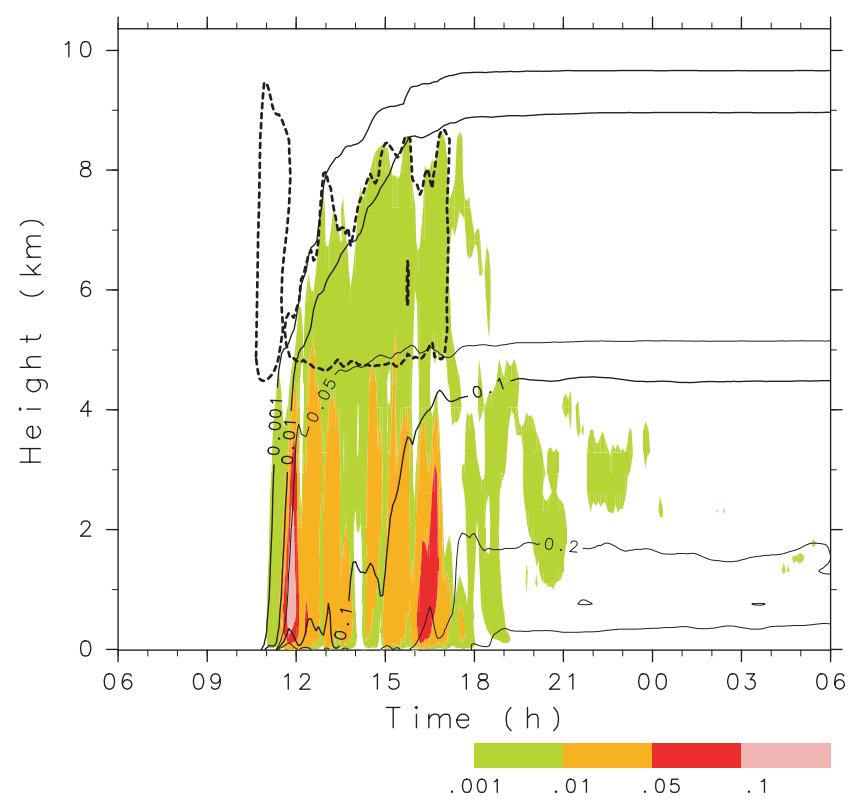

Fig. 5. Time-height section (area-averaged) of dust concentration (contoured, in $\mathrm{mg} \mathrm{m}^{-3}$ ), upward flux of dust (colored, in $\mathrm{mg}$ $\mathrm{m}^{-2} \mathrm{~s}^{-1}$ ), and cloud boundary (dotted).

emitted dust is floating in the boundary layer (Fig. 6b). After the increase of the dust ratio in the transition layer at $12 \mathrm{LT}$, the ratio of the free-tropospheric dust content gradually increases up to about $8 \%$. After the sunset, the ratios in the boundary layer, in the transition layer, and in the free troposphere amount to $79.8 \%$, $10.3 \%$, and $6.8 \%$, respectively.

In Fig. 5 it was shown that the convective motion in the boundary layer and cloud layer determines the vertical transport of dust in the atmosphere. These convective motions are considered to have other effects in producing the dust flux at the surface. Figure 7 shows the temporal variation of the vertical structure of momentum flux (product of perturbation horizontal and vertical winds). A significant amount of downward flux is identified below the $6-\mathrm{km}$ level, especially in the lowest $4 \mathrm{~km}$, during $10-18 \mathrm{LT}$; this suggests that convective motion transports high horizontal momentum downward to induce high winds at the surface and therefore to produce dust emission.

\section{Conclusions}

The present simulation seems to successfully reproduce the diurnal variability of fair-weather convective boundary layer over a desert, although the model settings are idealistic and simplified. The mean column burden of dust amounts to $0.92 \mathrm{~g} \mathrm{~m}^{-2}$ in one diurnal cycle; this value is in fair agreement with the remotesensing estimation (Kuji et al. 2005). It was shown that dry convection in the boundary layer and moist convection above the boundary layer play a significant role in determining the total amount of dust floating in the atmosphere. The convective activity plays another role in enhancing the surface winds and thus producing dust emission at the surface through the downward transport of high momentum in upper levels

In our simulation we employed the periodic condition both at lateral boundaries; thus, no clear-air inflow occurs once dust is transported above the surface. In reality, the horizontal advection of fresh or polluted air from the upstream locations also regulates the dust concentration in the free troposphere. The large-scale 

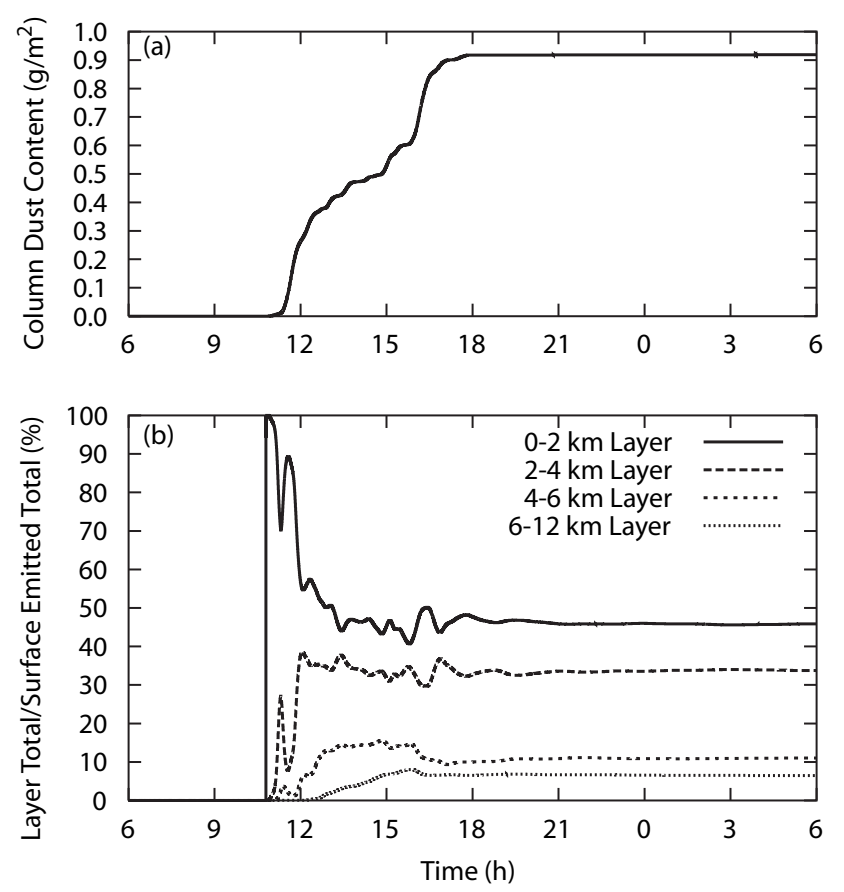

Fig. 6. Time series of (a) the mean column burden of dust ( $\mathrm{g}$ $\mathrm{m}^{-2}$ ) and the percentage ratio of the total dust amount at the $0-2,2-4,4-6$, and $6-12 \mathrm{~km}$ levels to the total dust amount emitted at the surface.

vertical motions may also determine the height of the dust-layer top. In spite of these, we consider that the present simulation framework with the use of a cloudresolving model provides a fundamental understanding of the dust transport processes associated with boundary-layer convection and cumulus convection in fairweather conditions. We are currently conducting a systematic set of simulations to further examine the mechanisms of dust transport and comparing the results with the lidar and sky-radiometer observations, which will be described in a future paper.

\section{Acknowledgments}

The comments from the two anonymous reviewers were acknowledged for improving the original manuscript. This study was supported by grants from the Special Coordination Fund for Promoting Science and Technology from MEXT and from Grant-in-Aid for Scientific Research from JSPS. The ARPS model was developed by The Center for Analysis and Prediction of Storms, The University of Oklahoma. The sounding data were obtained from the web site of Department of Atmospheric Sciences, University of Wyoming.

\section{References}

Cakmur, R. V., and R. L. Miller, 2004: Incorporating the effect of small-scale circulations upon dust emission in an atmospheric general circulation model. J. Geophys. Res., 109, D07201, doi:10.1029/2003JD004067.

Grabowski, W. W., X. Wu, and M. W. Moncrieff, 1996: Cloudresolving modeling of tropical cloud systems during Phase III of GATE. Part I: Two-dimensional experiments. J. Atmos. Sci., 53, 3684-3709.

Iwasaka, Y., T. Shibata, T. Nagatani, G. Y. Shi, Y. S. Kim, A. Matsuki, D. Trochkine, D. Zhang, M. Yamada, M. Nagatani, H. Nakata, Z. Shen, G. Li, B. Chen, and K.

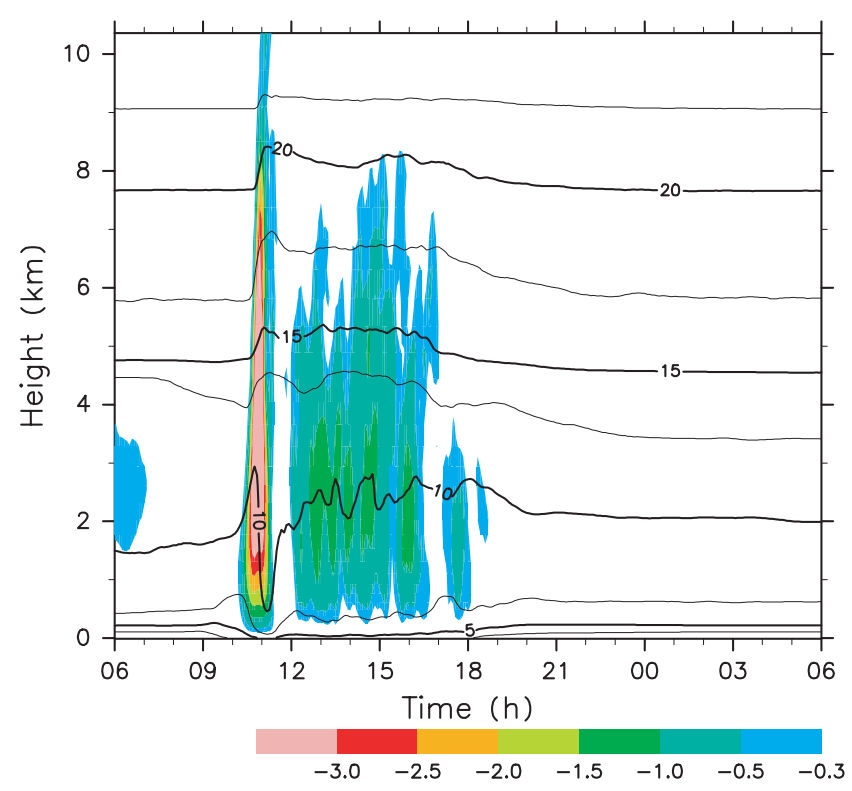

Fig. 7. Time-height section (area-averaged) of vertical flux (downward only) of horizontal momentum (colored, in $\mathrm{m}^{2} \mathrm{~s}^{-2}$ ) and east-west wind (contoured, in $\mathrm{m} \mathrm{s}^{-1}$ ).

Kawahira, 2003: Large depolarization ratio of free tropospheric aerosols over the Taklamakan Desert revealed by lidar measurements: Possible diffusion and transport of dust particles. J. Geophys. Res., 108, 8652, doi:10.1029/2002JD003267.

Kuji, M., N. Yamanaka, S. Hayashida, M. Yasui, A. Uchiyama, A. Yamazaki, and T. Aoki, 2005: Retrieval of Asian dust amount over land using ADEOS-II/GLI near UV data. SOLA, 1, 33-36.

Liu, M., and D. L. Westphal, 2001: A study of the sensitivity of simulated mineral dust production to model resolution. $J$. Geophys. Res., 106, 18099-18112.

Luo, C., N. Mahowald, and C. Jones, 2004: Temporal variability of dust mobilization and concentration in source regions. J. Geophys. Res., 109, D20202, doi:10.1029/2004JD004861.

Takemi, T., 2005: Explicit simulations of convective-scale transport of mineral dust in severe convective weather. $J$. Meteor. Soc. Japan, 83A, 187-203.

Takemi, T., 1999: Structure and evolution of a severe squall line over the arid region in northwest China. Mon. Wea. Rev., 127, 1301-1309.

Takemi, T., and N. Seino, 2005: Dust storms and cyclone tracks over the arid regions in east Asia in spring. J. Geophys. Res., 110, D18S11, doi:10.1029/2004JD004698.

Takemi, T., and T. Satomura, 2000: Numerical experiments on the mechanisms for the development and maintenance of long-lived squall lines in dry environments. J. Atmos. Sci., 57, $1718-1740$.

Xue, M., K. K. Droegemeier, and V. Wong, 2000: The Advanced Regional Prediction System (ARPS) - A multiscale nonhydrostatic atmospheric simulation and prediction tool. Part I: Model dynamics and verification. Meteor. Atmos. Physics, 75, 161-193.

Xue, M., K. K. Droegemeier, V. Wong, A. Shapiro, K. Brewster, F. Carr, D. Weber, Y. Liu, and D. Wang, 2001: The Advanced Regional Prediction System (ARPS) - A multiscale nonhydrostatic atmospheric simulation and prediction tool. Part II: Model physics and applications. Meteor. Atmos. Physics, 76, 143-165.

Yasui, M., J. Zhou, L. Liu, T. Itabe, K. Mizutani, and T. Aoki, 2005: Vertical profiles of aeolian dust in the desert atmosphere observed by a lidar in Shapotou, China. J. Meteor. Soc. Japan, 83A, 149-171.

Manuscript received 3 June 2005, accepted 1 August 2005 SOLA: http://www.jstage.jst.go.jp/browse/sola/ 